\title{
Induction of erythroid proliferation and differentiation by a trophoblast-specific cytokine involves activation of the JAK/STAT pathway
}

\section{T Bittorf, R Jaster, M J Soares ${ }^{1}$, J Seiler, J Brock, K Friese ${ }^{2}$ and H Müller ${ }^{2}$}

Institute of Medical Biochemistry, University of Rostock, Doberaner Str. 142, 18057 Rostock, Germany

${ }^{1}$ Department of Molecular and Integrative Physiology, University of Kansas Medical Center, Kansas City, Kansas 66160, USA

${ }^{2}$ Department of Obstetrics and Gynecology, University of Rostock, Doberaner Str. 142, 18057 Rostock, Germany

(Requests for offprints should be addressed to H Müller; Email: heiner.mueller@med.uni-rostock.de)

\begin{abstract}
Pregnancy is characterized by increased erythropoiesis within maternal and fetal compartments. The placenta has been shown to produce factors that stimulate erythropoiesis but convincing evidence for placental production of erythropoietin $(\mathrm{EPO})$ is still lacking. Prolactin-like protein E (PLP-E) was recently found to stimulate expression of the adult beta major globin gene in mouse erythroleukemia cells. Here we demonstrate that PLP-E transiently expressed in COS-7 cells stimulates proliferation and erythroid differentiation of murine and human erythroid progenitor cell lines. Electrophoretic mobility shift assays were used to show the activation of STAT5 by PLP-E in
\end{abstract}

the human erythroid cell line TF1. Furthermore, we compared the effects of PLP-E on murine myeloid FDCP1 cells which do not express EPO receptors (EPORs) with effects on cells genetically engineered to express functional EPORs. We provide evidence that PLP-E-dependent proliferation and STAT5 activation is independent of the expression of the EPOR. Taken together, these data suggest that PLP-E acts on specific receptors of erythroid-committed murine and human cells by the activation of intracellular signaling pathways promoting cell growth and differentiation.

Fournal of Molecular Endocrinology (2000) 25, 253-262

\section{INTRODUCTION}

Viviparity in mammals requires the dedication of maternal resources that go far beyond the limited provision with nutrients found in oviparous species. The formation of a separate ectodermal compartment, the trophoblast, and its subsequent assembly into a functional placenta represent pivotal developmental events. By establishing intimate contact with the maternal circulation, hemochorial placentation provides optimal gas exchange, supply of nutrients and waste disposal, but poses several challenges to the maternal organism and the developing fetus. Thus, the maternal response to pregnancy entails a variety of immunological, endocrine, metabolic and cardiorespiratory adaptations.

The placenta produces a wide array of hormones, cytokines and growth factors that are predicted to manipulate maternal physiology for fetal benefit. In rodents, ruminants and primates, proteins with a close structural relationship to the pituitary hormones prolactin (PRL) and growth hormone $(\mathrm{GH})$ are prominently expressed within the uteroplacental compartment (Soares et al. 1998a,b, Linzer \& Fisher 1999). Although all members of the family bear structural similarity to pituitary PRL, only the classical members, placental lactogens (PLs), represent PRL receptor (PRL-R) agonists. All other proteins of the PRL gene family do not bind to the PRL-R and constitute the group of nonclassical members. The mouse placental PRL gene family was recently expanded by several nonclassical members: decidual PRL-related protein, PRL-like protein-A (PLP-A), PLP-B, PLP-Ca, PLP-E, PLP-F and PLP-G (Lin et al. 1997a,b, Orwig et al. 1997, Dai et al. 1998, Müller et al. 1998a,b). This 
expansion was accompanied by an increased elaboration of functional insights. In addition to the well-characterized actions of PLs, nonclassical members of the PRL family that cannot bind to the PRL-R have been shown to bind and affect specific targets such as endothelial cells (Jackson et al. 1994), uterine natural killer cells (Müller et al. 1999) and megakaryocytes (Linzer \& Fisher 1999). Moreover, recent evidence suggests that PLP-E can stimulate erythropoiesis (Lin \& Linzer 1998) and induces megakaryocyte differentiation (Lin \& Linzer 1999).

The purpose of our investigation was to study the effects of PLP-E on proliferation and differentiation of murine and human erythroid progenitor cell lines and to examine the involvement of the erythropoietin (EPO) receptor (EPOR) and the Janus kinase/signal transducer and activator of transcription (JAK/STAT) pathway in the stimulation of erythropoiesis by PLP-E .

\section{MATERIALS AND METHODS}

\section{Expression of PLPs in COS-7 cells}

COS-7 cells were grown to $80 \%$ confluence in Dulbecco's modified Eagle's medium (DMEM; Gibco, Eggenstein, Germany) containing $20 \mathrm{mM}$ Hepes and supplemented with $10 \%$ fetal bovine serum (FBS). In this study, we used a cDNA for PLP-E which was originally independently characterized by two groups and published as PLP-E and PLP-G respectively (Lin et al. 1997b, Müller et al. 1998b). The cDNA clone for PLP-E (clone No. 557289, Genbank Accession AA111341, NID g1663220) was originally identified from the expression library 'Life Tech mouse embryo $10 \cdot 5$ dpc' and was obtained from IMAGE Consortium and Research Genetics, Huntsville, AL, USA (Lennon et al. 1996). The cDNA for PLP-A (Genbank Accession AF015562, NID g2353721), which was included for control purposes, has been described previously (Müller et al. 1998a). The cDNAs were cloned in the pCMV-SPORT2 eukaryotic expression vector (Life Technologies, Gaithersburg, MD, USA). Before introduction of the DNA into COS-7 cells, the sequences were completely verified by sequencing both strands.

Anion-exchange resin (Qiagen $\mathrm{GmbH}$, Hilden, Germany)-purified nonlinearized plasmid DNA $(20 \mu \mathrm{g})$ was electroporated into COS-7 cells using a Bio-Rad (Richmond, CA, USA) Gene Pulser $(960 \mu \mathrm{F}, 250 \mathrm{~V})$. Transfections with the empty expression vector were included as controls. After $24 \mathrm{~h}$ of growth as adherent monolayers the medium was replaced by FBS-free culture medium and the cells incubated for another $24 \mathrm{~h}$. The conditioned culture medium was harvested, clarified by centrifugation $(12000 \boldsymbol{g})$, sterile-filtered $(0.22 \mu \mathrm{m})$, and stored at $-20{ }^{\circ} \mathrm{C}$ until used. Supernatants from three separate transfections were tested with similar results.

\section{Generation of antipeptide antibodies for mouse PLP-E}

In order to evaluate the effects of PLP-E, protein expression in the transfected cells had to be confirmed. Therefore, we generated a specific immunological probe to mouse PLP-E. The 16 mer GATENVADYTLWSGLE (amino acids 195-210) was selected based on its relative hydrophilicity/ hydrophobicity, the presence of $\beta$-turns and sequence comparison with other members of the PRL-GH family as previously described (Deb et al. 1989). Following synthesis of the oligopeptide and its coupling to the carrier keyhole limpet hemocyanin (KLH) by using 1-ethyl-3-(3',3'-dimethylaminopropyl)-carbodiimide hydrochloride, rabbits were immunized with the oligopeptide-KLH preparations (PepScan Immunoanalytik GmbH, Berlin, Germany). Blood was collected prior to immunization, as well as 6 and 12 weeks after immunization. Reactivity of the pre-immune sera and the antipeptide antisera were characterized with a peptide ELISA as previously described (Deb et al. 1989).

\section{Characterization of PLP-E protein expression by Western blotting}

Supernatants of transfected COS-7 cells were diluted with one volume of SDS sample buffer (50 $\mathrm{mM}$ Tris, pH $6 \cdot 8,10 \%$ glycerol, $1 \cdot 5 \%$ SDS, $4 \cdot 2 \% \beta$-mercaptoethanol, $0 \cdot 01 \%$ bromophenol blue) and boiled for $3 \mathrm{~min}$. Proteins $(50 \mu \mathrm{l}$ of crude supernatant) were separated through $10 \%$ SDSpolyacrylamide gels and transferred to nitrocellulose membranes (Hybond-ECL; Amersham International, Amersham, Bucks, UK) as described previously (Bittorf et al. 1994). Membranes were blocked with $1 \%$ BSA and incubated with antiPLP-E or anti-PLP-A antiserum (1:500). The PLP-A antiserum was described previously (Müller et al. 1998a). After a final incubation with a horseradish peroxidase-labeled anti-rabbit Ig antibody, blots were developed using the ECL system (Amersham).

\section{Evaluation of PRL-like biological activity}

Lactogenic biological activities were assessed using a rat $\mathrm{Nb2}$ lymphoma cell proliferation assay 
(Tanaka et al. 1980, Müller et al. 1998c). Nb2 lymphoma cells were routinely grown in Fischer's medium supplemented with $50 \mu \mathrm{M} \quad \beta$-mercaptoethanol, $100 \mathrm{U} / \mathrm{ml}$ penicillin, $100 \mu \mathrm{g} / \mathrm{ml}$ streptomycin, 10\% horse serum (HS) and 10\% FBS (maintenance medium (MM)) in an atmosphere of $5 \% \mathrm{CO}_{2} / 95 \%$ air at $37{ }^{\circ} \mathrm{C}$. Twenty-four hours before initiation of the assay, cells were harvested, washed with Fischer's medium containing only 10\% HS (stationary medium (SM)), and diluted to a concentration of 100000 cells $/ \mathrm{ml}$. At the initiation of the assay, cells were washed and transferred into $16 \mathrm{~mm}$ wells (100 000 cells/ml per well) of a $24-w e l l$ culture plate. Ovine PRL (oPRL) or serum-free conditioned media from COS-7 cells transiently transfected with PLP-E-cDNA or empty vector were added at various concentrations and the cells incubated for an additional $72 \mathrm{~h}$. Triplicate samples were collected and counted in a hematology analyzer (Cell-Dyn 1600; Abbott, Wiesbaden, Germany).

\section{Hematopoietic cell lines}

The murine erythroid progenitor cell line J2E (Busfield \& Klinken 1992) was grown in suspension culture in DMEM (Gibco) supplemented with $10 \%$ FBS. Cells were resuspended daily at a density of $1.5 \times 10^{5}$ cells $/ \mathrm{ml}$. The human erythroleukemia cell line TF1 (Kitamura et al. 1989) was cultivated in RPMI 1640 (Gibco), supplemented with 10\% FBS and $7.5 \mathrm{ng} / \mathrm{ml}$ recombinant human granulocytemacrophage colony-stimulating factor (GM-CSF; Boehringer, Mannheim, Germany). The murine myeloid FDCP1 cells grow in the presence of interleukin-3 (IL-3) and are not responsive to EPO. The cells were propagated in Iscove's modified Dulbecco's medium (Gibco) supplemented with $10 \%$ FBS. IL-3 was provided as conditioned supernatant $(5 \% \mathrm{v} / \mathrm{v})$ of WEHI 3B cells (Ymer et al. 1985). Parental FDCP1 cells were transfected by electroporation with the EPOR cDNA (D'Andrea et al. 1989) cloned into the expression vector pcDNA3 (Invitrogen Corp., Carlsbad, CA, USA). Stably transfected cells were selected in G418 $(1 \mathrm{mg} / \mathrm{ml})$ and by their ability to grow in response to EPO.

Recombinant EPO (Cilag GmbH, Sulzbach, Germany) and GM-CSF were used at concentrations of $5 \mathrm{U} / \mathrm{ml}$ and $10 \mathrm{U} / \mathrm{ml}$ respectively. These concentrations were found to result in a maximum stimulation of receptor activities. Unless otherwise stated, conditioned media from COS-7 cells were used at a final concentration of $20 \%$. All experiments included controls using medium conditioned by COS-7 cells transfected with the empty expression vector.

\section{Cell proliferation assay and benzidine staining}

Cell proliferation was analyzed by $\left[{ }^{3} \mathrm{H}\right]$ thymidine incorporation. Cells $\left(10^{4}-5 \times 10^{4}\right)$ were pulsed with $0.6 \mu \mathrm{Ci}\left[{ }^{3} \mathrm{H}\right]$ thymidine $(83 \mathrm{Ci} / \mathrm{mmol})$ for $4 \mathrm{~h}$ as described previously (Jaster et al. 1996). DNA was harvested onto glass fiber filters and assayed by liquid scintillation counting. Cell viability was assessed by trypan blue exclusion. Benzidine staining was used to determine the number of hemoglobin-synthesizing cells (Jaster et al. 1996).

\section{Preparation of nuclear extracts and electromobility shift assay (EMSA)}

Nuclear extracts were prepared essentially as described previously (Tilbrook et al. 1996). For EMSAs, nuclear proteins corresponding to $10^{5}$ cells were incubated with $16 \mathrm{fmol}$ double-stranded oligonucleotide derived from the bovine $\beta$-casein promoter (5'-AGATTTCTAGGAATTCAAATC$\left.3^{\prime}\right)$. The oligonucleotides were end-labeled with $\left[\gamma-{ }^{32} \mathrm{P}\right] \mathrm{ATP}$ (Amersham) by polynucleotide kinase. The shift assays were performed in a total volume of $20 \mu \mathrm{l}$ in the following buffer: $10 \mathrm{mM}$ Tris- $\mathrm{HCl}(\mathrm{pH}$ $7 \cdot 5$ ), $50 \mathrm{mM}$ potassium chloride, $0.1 \mathrm{mM}$ EDTA, $1 \mathrm{mM}$ dithiothreitol, $1 \mathrm{mg} / \mathrm{ml}$ BSA, $5 \%$ glycerol, $0 \cdot 1 \%$ NP40, $1 \mathrm{mM}$ Pefabloc (Boehringer). The reactions, also containing poly $(\mathrm{dI}-\mathrm{dC}) 1 \mathrm{mg} / \mathrm{ml}$ (Boehringer), were performed at room temperature for $30 \mathrm{~min}$ and initiated by the addition of nuclear extract. Supershift analysis was done by including $0.5 \mu \mathrm{g}$ of an antibody directed against the carboxyterminal part of STAT5B (Santa Cruz Biotechnology, Santa Cruz, CA, USA) at $4{ }^{\circ} \mathrm{C}$ for an additional $20 \mathrm{~min}$. Complexes were analyzed by electrophoretic separation on a $6 \%$ polyacrylamide gel in $0 \cdot 25 \times$ TBE buffer.

\section{Statistical analysis}

Raw data were analyzed by one-way ANOVA. The source of variation from significant $\mathrm{F}$ ratios was determined with Student's two-tailed $t$-test. The Wilcoxon signed ranks test was used to examine percentage data. For all tests, the statistical software package SPSS 9.0 (SPSS Inc., Chicago, IL, USA) was applied. Differences were considered significant if $P<0 \cdot 05$.

\section{RESULTS}

\section{Expression of recombinant PLP-E}

Western blot analysis revealed that the transfection of COS-7 cells with the mouse PLP-E cDNA 


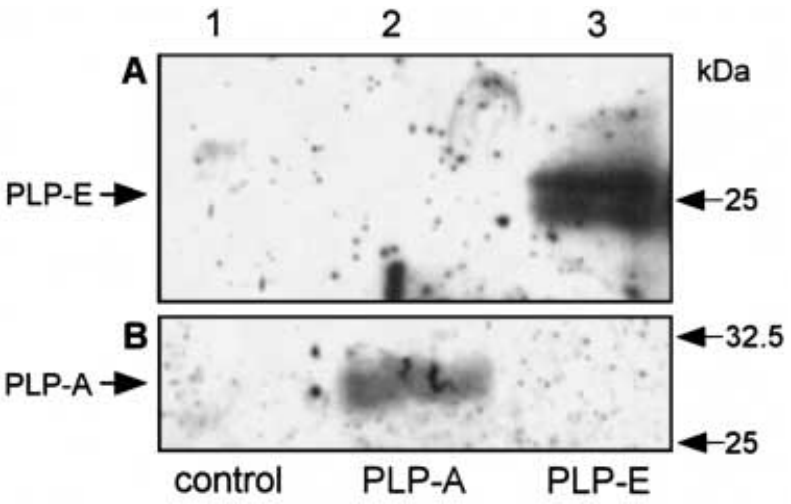

FIGURE 1. Demonstration of PLP-E protein expression by Western blotting. Supernatants of COS-7 cells transfected with mouse PLP-E cDNA, PLP-A cDNA and empty vector (control) were separated on a $10 \%$ SDS-polyacrylamide gel. Following transfer to a nitrocellulose membrane and blocking with $1 \%$ BSA, the membranes were incubated with rabbit antisera (1:500) to PLP-E (A) and PLP-A (B). After a final incubation with a horseradish peroxidase-labeled anti-rabbit Ig antibody, blots were developed using the ECL system.

resulted in the expression of the respective protein. The PLP-E protein was identified using an antipeptide antibody raised against amino acids 195-210 of the mouse PLP-E sequence (Fig. 1A). The antibody detects a doublet of proteins, which is probably caused by the expression of differentially glycosylated isoforms of PLP-E. To verify the specificity we analyzed the supernatants with an antibody directed against PLP-A (Fig. 1B). This antibody detects an immunoreactive protein species in PLP-A but not in PLP-E or control supernatants.

\section{PLP-E does not signal via the PRL-R}

To exclude the possibility that PLP-E activates the PRL-R, we tested the effect of the recombinant protein on rat $\mathrm{Nb} 2$ lymphoma cells. PLP-E was not capable of stimulating the proliferation of rat $\mathrm{Nb} 2$ lymphoma cells (Fig. 2). Rat Nb2 lymphoma cell proliferation is dependent on activation of the PRL-R signaling pathway, which can be achieved by PRL or other ligands capable of interacting with the PRL-R, such as PLs (Tanaka et al. 1980, Müller et al. 1998c).

\section{Effects of PLP-E on the proliferative response of hematopoietic cell lines}

The growth-stimulating activity of PLP-E was analyzed by $\left[{ }^{3} \mathrm{H}\right]$ thymidine incorporation assays.

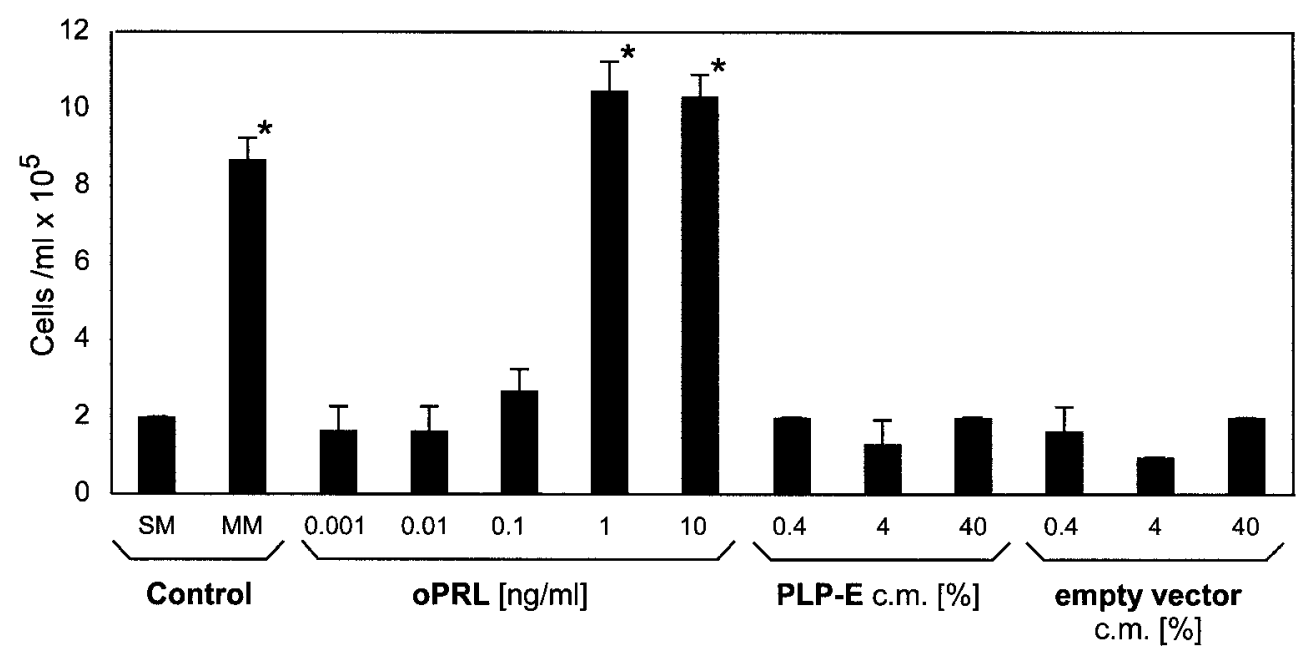

FIGURE 2. Effects of PLP-E on rat Nb2 lymphoma cell proliferation. PRL-like biological activities were assessed by use of the rat $\mathrm{Nb} 2$ lymphoma cell proliferation assay. $\mathrm{Nb} 2$ lymphoma cells were grown in MM. Twenty-four hours before initiation of the assay, cells were harvested, washed with SM, and diluted to a concentration of $100000 \mathrm{cells} / \mathrm{ml}$. At the initiation of the assay, cells were washed and transferred into $16 \mathrm{~mm}$ wells $(100000 \mathrm{cells} / \mathrm{ml}$ per well) of a 24-well culture plate. oPRL, conditioned medium (c.m.) of COS-7 cells transfected with PLP-E, or empty vector was added at various concentrations and the cells incubated for an additional $72 \mathrm{~h}$ and then counted. Treatments were performed in triplicate. Results are presented as means \pm S.D.. The oPRL-treated cultures show significantly stimulated proliferation of the Nb2 lymphoma cells compared with control cells in SM $(* P<0 \cdot 05)$. Note that PLP-E did not stimulate Nb2 proliferation. 

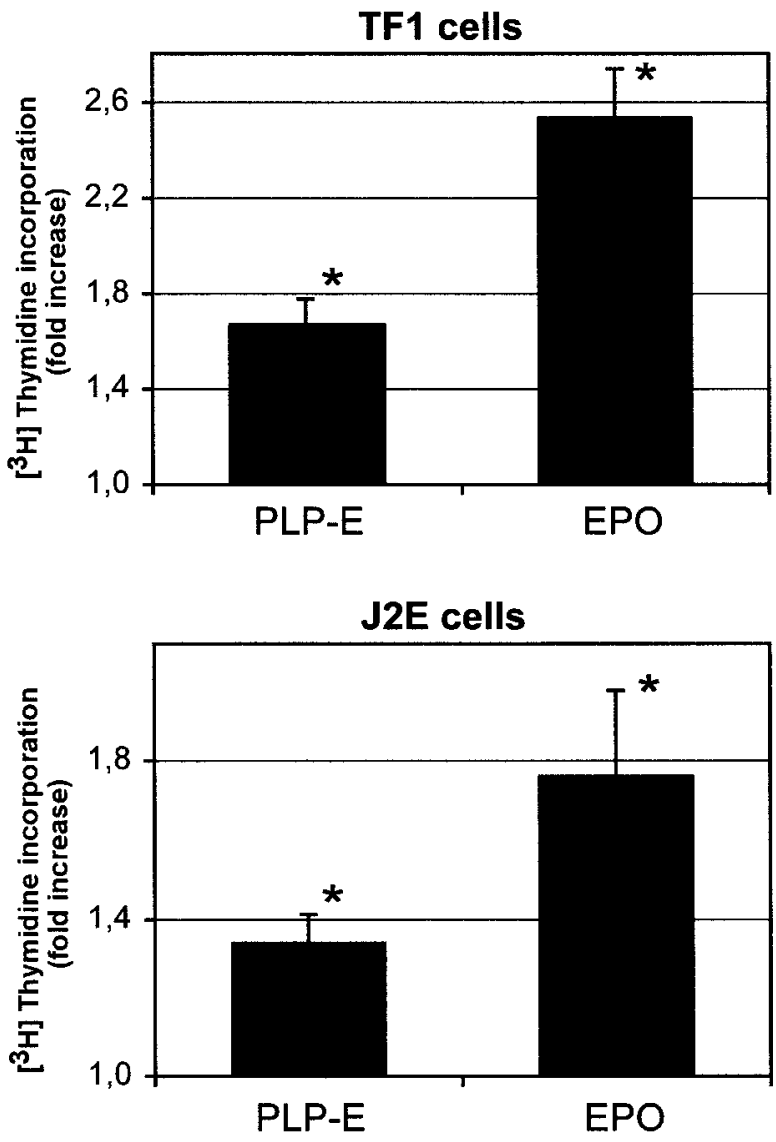

FIGURE 3. PLP-E-dependent proliferation in J2E and TF1 cells. Cells were grown in the presence of PLP-Econditioned media or EPO $(5 \mathrm{U} / \mathrm{ml})$ and pulsed with $\left[{ }^{3} \mathrm{H}\right]$ thymidine as described. Results indicate the ratio of values derived from stimulated cells vs control values (cells incubated with supernatant of COS-7 cells transfected with an empty vector) and represent the mean of five independent experiments. Results are presented as means \pm S.E.M. Note that EPO and PLP-E significantly stimulated the proliferation of murine and human erythroid progenitor cells $(* P<0 \cdot 05)$.

Both human (TF1) and mouse (J2E) erythroleukemic cell lines were examined. TF1 cells are known to be responsive to a panel of cytokines, including EPO, IL-3 and GM-CSF, whereas the J2E cells can grow independently of the addition of exogenous cytokines but show an increased proliferation rate after addition of EPO (Busfield \& Klinken 1992). Furthermore, J2E cells as well as TF1 cells differentiate along the erythroid pathway upon treatment with EPO. The effects of PLP-Econtaining conditioned COS-7 media were normalized using the supernatant of $\mathrm{COS}-7$ cells transfected with the empty vector (control; Fig. 3).
EPO-induced responses are shown as a positive control.

In J2E cells, recombinant EPO and PLP-E (but not the related PLP-A; data not shown) showed significant growth-promoting activities (Fig. 3). In TF1 cells, we found a similar response to both factors (Fig. 3). The results shown were calculated using data from five assays and were reproducible with supernatants produced by independent transfections.

\section{PLP-E induces erythroid differentiation of J2E and TF1 erythroleukemic cell lines}

To further investigate the biological effects of PLP-E on hematopoietic cells we analyzed its ability to induce erythroid maturation. Both J2E and TF1 cells synthesize hemoglobin and undergo morphological alterations in response to EPO (Gobert et al. 1996, Lin et al. 1996). Hemoglobincontaining cells were detected by benzidine staining. PLP-E induced a significant increase of hemoglobin synthesis in both cell lines, similar to the EPO-induced response (Fig. 4).

\section{PLP-E induces the DNA-binding activity of STAT5 in TF1 cells}

Many cytokines are known to induce the JAK/ STAT pathway by the activation of specific sets of JAK tyrosine kinases and transcription factors of the STAT family. In view of the biological activities of PLP-E seen above we were interested in its ability to activate this pathway. Nuclear extracts from PLP-E as well as cytokine-stimulated TF1 cells were prepared and subjected to EMSA using a STAT binding site derived from the $\beta$-casein promoter. As shown in Fig. 5, EPO, GM-CSF and PLP-E induced a DNA-protein complex. In an attempt to identify the proteins of the complex, we employed supershift analysis using an antibody specific for the carboxy-terminal domain of STAT5b. All induced complexes undergo a complete mobility shift indicating the presence of STAT5 whereas antibodies to other STAT species (STAT1, 3) display no interaction (data not shown). The induction of STAT5 DNA-binding activity is not restricted to TF1 cells since the analysis of $\mathrm{J} 2 \mathrm{E}$ cells revealed qualitatively identical results (data not shown).

\section{Induction of proliferation and STAT5 activation by PLP-E is independent of the expression of the EPOR}

The effects of PLP-E on the proliferation and differentiation of erythroleukemic cell lines documented 

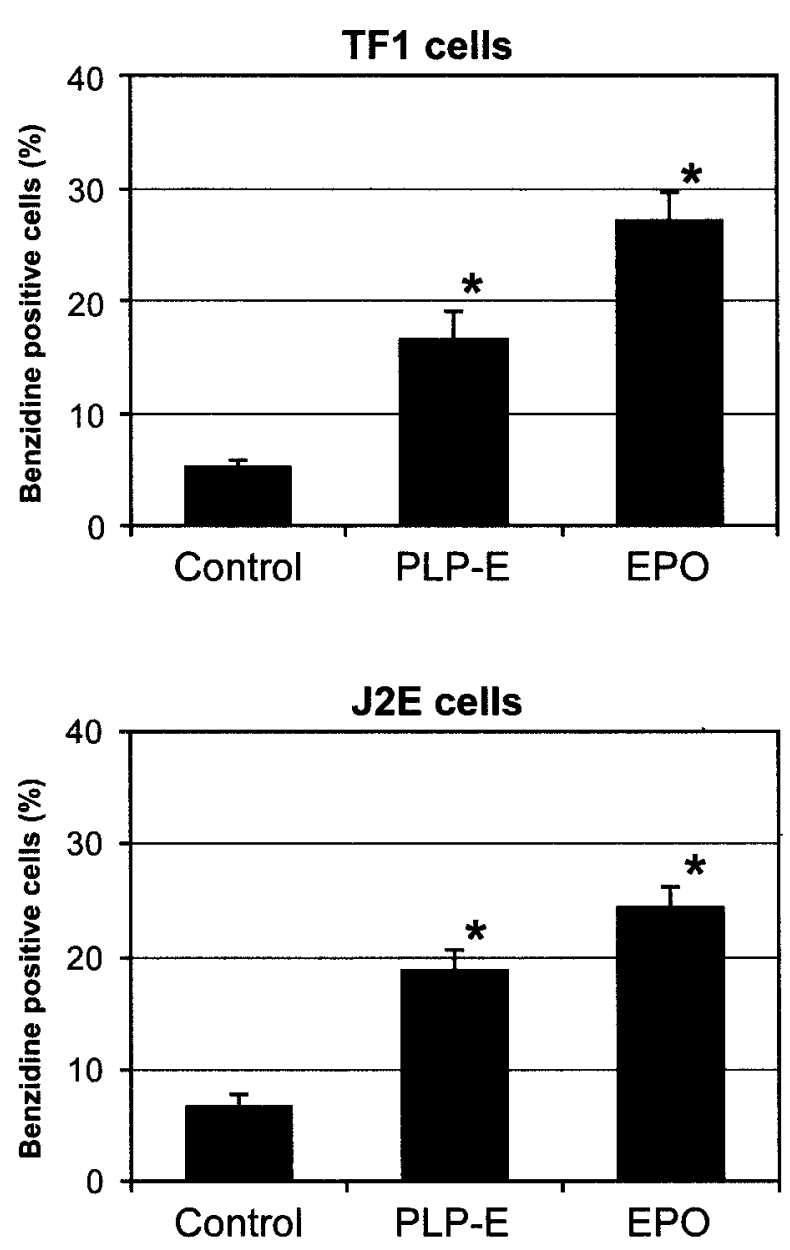

FIGURE 4. PLP-E-dependent erythroid differentiation in J2E and TF1 cells. Cell cultures were established at $10^{5}$ cells $/ \mathrm{ml}$ and exposed to EPO $(5 \mathrm{U} / \mathrm{ml})$ or PLP-Econditioned media as described. Benzidine-positive cells were determined $48 \mathrm{~h}$ later. These data are calculated from five independent experiments and are presented as means \pm s.E.M. Note that EPO and PLP-E significantly stimulated the erythroid differentiation of murine and human erythroid progenitor cells $(* P<0 \cdot 05)$.

above are very similar to EPO-induced biological activities. Therefore, it is tempting to speculate that PLP-E might activate the EPOR itself to induce erythroid-specific cellular reactions. To investigate this possibility we used IL-3-dependent FDCP1 cells, which do not express endogeneous EPORs (FDCP1 WT), and compared them with cells stably transfected with the EPOR cDNA (FDCP1 EPOR). Figure 6 shows the results of proliferation assays using both cell types. As expected, EPOR-expressing cells respond to EPO by enhanced proliferation and display the same IL-3-dependent proliferation as untransfected
FDCP1 cells. PLP-E significantly enhances the $\left[{ }^{3} \mathrm{H}\right]$ thymidine incorporation in FDCP1 WT cells, indicating that this factor exerts its effects independently of the EPOR expression. Interestingly, the mitogenic effect of PLP-E is reduced in EPOR-transfected cells.

Additional experiments were done to extend these data to the intracellular signaling capabilities of both cell types (Fig. 7). EMSA revealed that PLP-E is a potent activator of STAT5 both in FDCP1 WT and in FDCP1 EPOR cells. In contrast, EPO induces STAT5 activation in FDCP1 EPOR cells only, providing further evidence for the EPOR-independent action of PLP-E.

\section{DISCUSSION}

Hematopoiesis is controlled by a group of polypeptide ligands which signal through a structurally related set of transmembrane receptors to regulate the lineage-specific development of progenitor cells (Moritz et al. 1997). These cytokines induce specific signaling pathways to promote viability, proliferation and differentiation of hematopoietic cells. During embryonic development, erythropoiesis occurs in two distinct forms (McGann et al. 1997, Silver \& Palis 1997). In the mouse, the first 'primitive' form is represented by nucleated erythroblasts that begin to differentiate within the blood vessels of the extraembryonic yolk sac on the eighth gestational day. The second 'definitive' form of erythropoiesis is thought to originate from hematopoietic progenitors that emerge from endothelial cells in the yolk sac, the vitelline and umbilical arteries, and in the aorta/ genital ridge/mesonephros region. Beginning on gestational day 10 , anucleate erythrocytes differentiate within the fetal liver. Towards term, the bone marrow of the fetus becomes the dominant site of erythropoiesis and the production of red cells is approximately 3-5 times that of adult steady state levels (Moritz et al. 1997, Silver \& Palis 1997). A significant increase in blood volume characterizes maternal adaptation to pregnancy. In the human, this is reflected by a $50 \%$ increase in plasma volume, an $18-25 \%$ increase in red cell mass and 4 -fold increased EPO levels (Letsky 1995).

The glycoprotein EPO is synthesized in the fetal liver and the adult kidney and has been shown to be the primary growth factor involved in the regulation of red blood cell production (Moritz et al. 1997). Gene targeting studies revealed that both EPO and EPOR genes are essential for definitive erythropoiesis in vivo (Wu et al. 1995, Lin et al. 1996). It is well established that maternal EPO does not cross the placenta into the fetal compartment (Schneider 


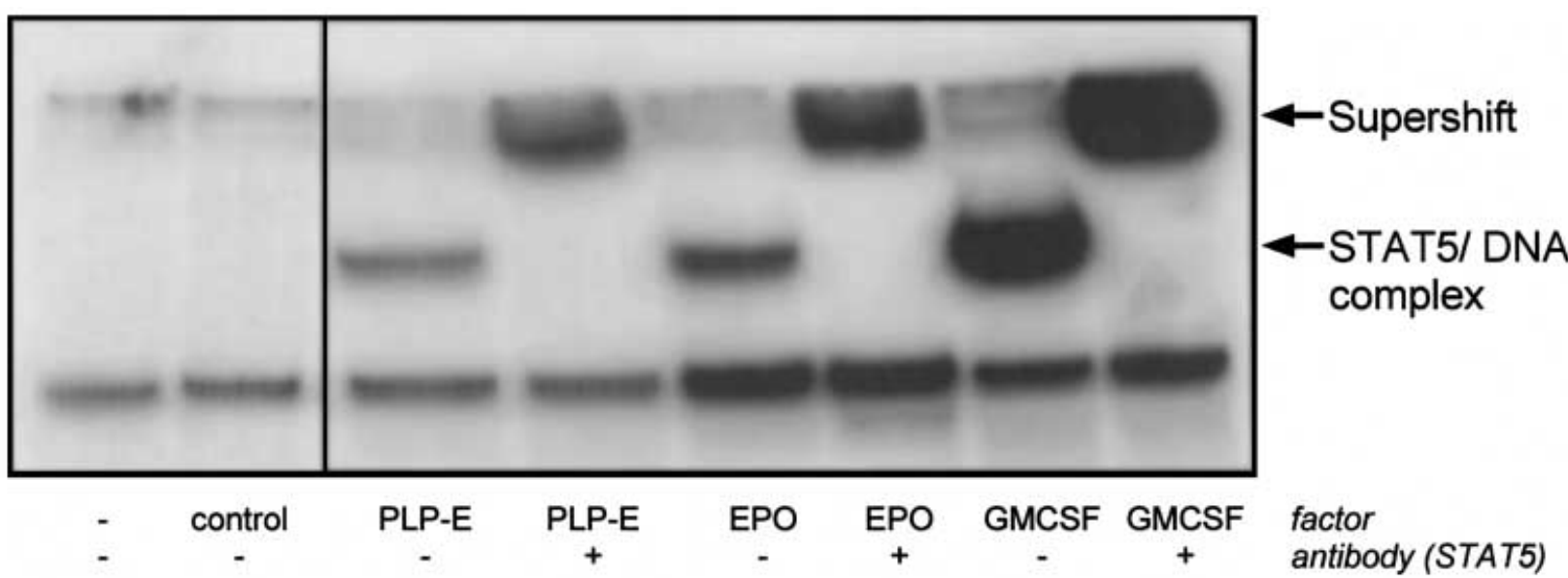

FIgURE 5. Activation of STAT5 DNA-binding activity in PLP-E- and cytokine-stimulated TF1 cells. Cells were deprived of GM-CSF for $24 \mathrm{~h}$ and stimulated for $15 \mathrm{~min}$ with EPO (5 U/ml), GM-CSF (10 U/ml), or serum-free conditioned medium of COS-7 cells transfected with PLP-E or empty vector. Nuclear extracts were prepared and subjected to EMSA as described. Note that PLP-E, EPO and GM-CSF induced the formation of a protein-DNA complex that could be completely supershifted by an antibody to STAT5.

\& Malek 1995). However, expression of the EPOR in trophoblast cells from murine and human placentae has been shown at the mRNA and protein level (Sawyer et al. 1989, Fairchild \& Conrad 1999). Although EPO immunoreactivity was demonstrated in human placenta, its mRNA expression could not be confirmed by Northern blotting (Conrad et al. 1996). It is therefore assumed that the positive immunostaining represents EPOR-bound EPO (Moritz et al. 1997).

Trophoblast cells produce factors that stimulate erythropoiesis (Brewer et al. 1992). Recent evidence suggests that members of the PRL gene family are involved in this activity (Lin \& Linzer 1998). The placental PRL gene family represents a group of structurally related proteins specifically expressed during pregnancy by trophoblast cells of the placenta and/or adjacent decidua (Soares et al. 1998b). Several members of this family (PRL and PLs) signal via the PRL-R. The PRL-R as well as the receptors for $\mathrm{GH}$ and thrombopoietin (TPO) belong to the class I cytokine receptor family and are able to substitute for the EPOR in erythroid development (Golde et al. 1977, Kieran et al. 1996, Socolovsky et al. 1998). It seems therefore possible that members of the PRL family utilize signaling mechanisms that evolved from class I cytokine receptor prototypes. The presented data show that PLP-E of the mouse placenta induces proliferation and differentiation of erythroid precursors. These effects were demonstrated in murine and human cell lines. PLP-E is produced in the mouse placenta by trophoblast giant cells (Lin et al. 1997b, Müller
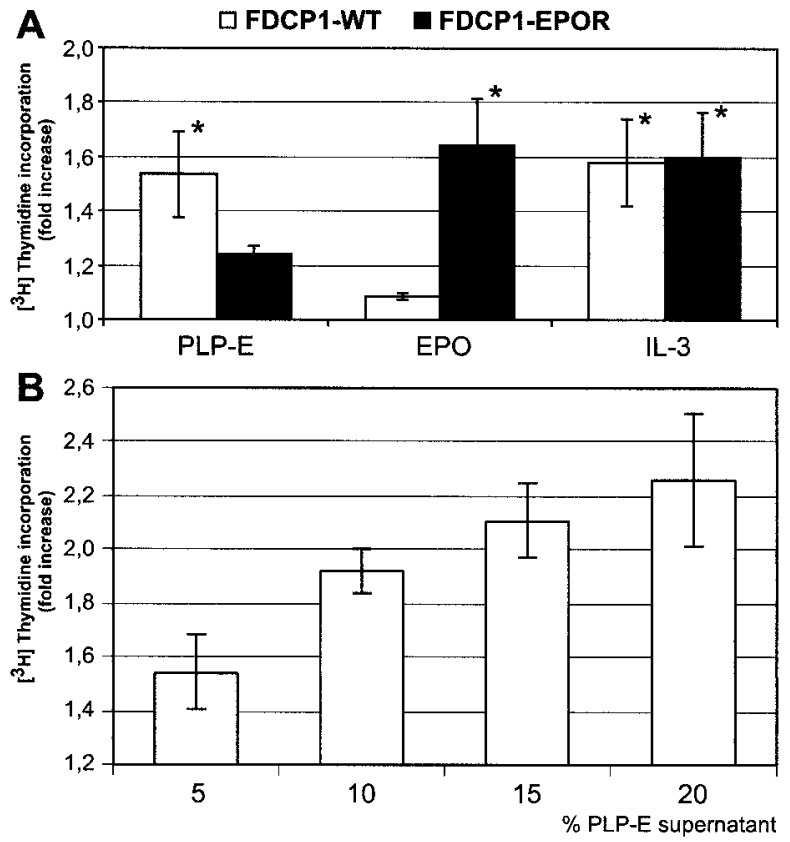

FIGURE 6. Comparative analysis of FDCP1 WT and FDCP1 EPOR cells. (A) $\left[{ }^{3} \mathrm{H}\right]$ thymidine incorporation after stimulation with PLP-E-conditioned media, EPO and IL-3. Results indicate ratios of values derived from stimulated cells vs control values and represent the means \pm s.E.M. of five independent experiments.

EPOR-expressing cells respond to EPO by enhanced proliferation and display the same IL-3-dependent proliferation as untransfected FDCP1 cells. Note that PLP-E significantly stimulated proliferation in wild-type FDCP1 cells that lack the EPOR $(* P<0 \cdot 05)$. (B) FDCP1 WT cells were stimulated with different amounts of PLP-E supernatant and analyzed as above. 


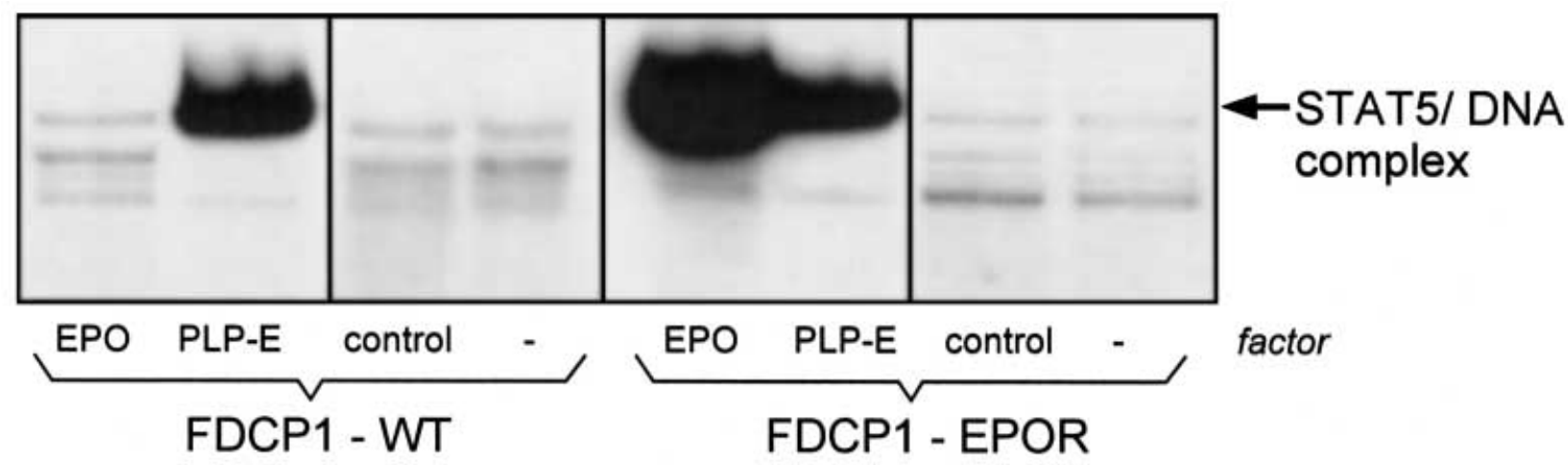

FIGURE 7. PLP-E- and EPO-induced activation of STAT5 DNA-binding activity in FDCP1 WT and FDCP1 EPOR cells. Cells were deprived of IL-3 for $24 \mathrm{~h}$ and stimulated for $15 \mathrm{~min}$ with EPO (5 U/ml) or serum-free conditioned medium of COS-7 cells transfected with PLP-E or empty vector. Nuclear extracts were prepared and subjected to EMSA as described. Note that PLP-E induced the formation of a STAT5/DNA complex in wild-type and EPOR-transfected FDCP1 cells whereas EPO activates STAT5 only in FDCP1 cells that express the EPOR.

et al. 1998b). Within the uteroplacental compartment, PLP-E is positioned to potentially affect maternal as well as fetal hematopoietic targets. This dual direction of transport has been demonstrated for the PRL family member proliferin (PLF), which is also secreted by trophoblast giant cells. PLF associates with the yolk sac and has been shown to be present in maternal serum and in fetal compartments (Lee et al. 1988, Jackson \& Linzer 1997). Thus, PLP-E may very well affect yolk sac erythropoiesis. This speculation is indirectly supported by the recent observation showing that yolk sac erythropoiesis is not exclusively dependent on EPO (McGann et al. 1997).

To further elucidate the molecular basis of PLP-E action, we studied the induction of signaling events known to be involved in cytokine-mediated gene activation in hematopoietic cells. Our data show that PLP-E induces the DNA-binding activity of STAT5, a transcription factor which has been shown to be a part of the EPO-dependent signaling machinery (Gouilleux et al. 1995, Liu et al. 1995). The essential role of STAT5 (which was originally identified as a mediator of lactogenic signaling (Liu et al. 1995)) in fetal hematopoiesis has been established using STAT5a - /5b - mouse embryos (Socolovsky et al. 1999), which are severely anemic. In contrast, adult mice that are nullizygous for STAT5 show apparently normal hematopoiesis (Teglund et al. 1998). It has been reported that EPORs defective in STAT5 activation are deficient in supporting mitogenesis (Gobert et al. 1996) and that a constitutively active STAT5 mutant promotes cytokine-independent proliferation after transfection in IL-3-dependent cells (Onishi et al. 1998). The activation of STAT5, however, is not unique to the EPOR (Teglund et al. 1998). Several hematopoietin receptors and even nonhematopoietic receptors activate STAT5. Recent studies using receptor hybrids composed of the extracellular EPOR domain and the cytoplasmic part of the GH receptor, the TPO receptor and the GM-CSF receptor show that these receptors activate appropriate signal transduction pathways to support erythroid development in vitro and in vivo (Goldsmith et al. 1998). Moreover, the receptors for PRL, GH and TPO, like the EPOR, belong to the class I cytokine receptor family, form homodimers upon activation, activate STAT5, and are able to substitute for EPOR in erythroid development (Golde et al. 1977, Kieran et al. 1996, Goldsmith et al. 1998, Socolovsky et al. 1998). Our experiments using EPOR expressing/nonexpressing cells provide evidence that the EPOR is not involved in the PLP-E-dependent STAT5 activation. The molecular background of the reduced mitogenic response in PLP-E-stimulated FDCP1 EPOR cells, which may occur at the level of intracellular signal transduction, remains to be established.

In conclusion, we hypothesize that PLP-E utilizes receptors that are functional in activating erythroid-specific pathways independently of the $\mathrm{EPO} / \mathrm{EPOR}$ system and that these structures are potentially conserved.

\section{REFERENCES}

Bittorf T, Jaster R \& Brock J 1994 Rapid activation of the MAP kinase pathway in hematopoietic cells by erythropoietin, granulocyte-macrophage colony-stimulating factor and interleukin-3. Cellular Signalling 6 305-311. 
Brewer CA, Adelson MD \& Elder RC 1992 Erythrocytosis associated with a placental-site trophoblastic tumor. Obstetrics and Gynecology 79 846-849.

Busfield SJ \& Klinken SP 1992 Erythropoietin-induced stimulation of differentiation and proliferation in $\mathrm{J} 2 \mathrm{E}$ cells is not mimicked by chemical induction. Blood $80412-419$.

Conrad KP, Benyo DF, Westerhausen-Larsen A \& Miles TM 1996 Expression of erythropoietin by the human placenta. FASEB Fournal 10 760-768.

Dai G, Chapman BM, Liu B, Orwig KE, Wang D, White RA, Preuett B \& Soares MJ 1998 A new member of the mouse prolactin (PRL)-like protein-C subfamily, PRL-like protein-C alpha: structure and expression. Endocrinology 139 $5157-5163$.

D'Andrea AD, Lodish HF \& Wong GG 1989 Expression cloning of the murine erythropoietin receptor. Cell $\mathbf{5 7}$ 277-285.

Deb S, Hashizume K, Boone K, Southard JN, Talamantes F, Rawitch A \& Soares MJ 1989 Antipeptide antibodies reveal structural and functional characteristics of rat placental lactogen-II. Molecular and Cellular Endocrinology 63 45-56.

Fairchild BD \& Conrad KP 1999 Expression of the erythropoietin receptor by trophoblast cells in the human placenta. Biology of Reproduction 60 861-870.

Gobert S, Chretien S, Gouilleux F, Muller O, Pallard C, Dusanter-Fourt I, Groner B, Lacombe C, Gisselbrecht S \& Mayeux P 1996 Identification of tyrosine residues within the intracellular domain of the erythropoietin receptor crucial for STAT5 activation. EMBO fournal 15 2434-2441.

Golde DW, Bersch N \& Li CH 1977 Growth hormone: speciesspecific stimulation of erythropoiesis in vitro. Science 196 $1112-1113$.

Goldsmith MA, Mikami A, You Y, Liu P \& Longmore GD 1998 Absence of cytokine receptor-dependent specificity in red blood cell differentiation in vivo. PNAS 95 7006-7011.

Gouilleux F, Pallard C, Dusanter-Fourt I, Wakao H, Haldosen LA, Norstedt G, Levy D \& Groner B 1995 Prolactin, growth hormone, erythropoietin and granulocyte-macrophage colony stimulating factor induce MGF-Stat5 DNA binding activity. EMBO Fournal 14 2005-2013.

Jackson D \& Linzer DIH 1997 Proliferin transport and binding in the mouse fetus. Endocrinology 138 149-155.

Jackson D, Volpert OV, Bouck N \& Linzer DIH 1994 Stimulation and inhibition of angiogenesis by placental proliferin and proliferin-related protein. Science $\mathbf{2 6 6}$ 1581-1584.

Jaster R, Bittorf T, Klinken SP \& Brock J 1996 Inhibition of proliferation but not erythroid differentiation of J2E cells by rapamycin. Biochemical Pharmacology 51 1181-1185.

Kieran MW, Perkins AC, Orkin SH \& Zon LI 1996 Thrombopoietin rescues in vitro erythroid colony formation from mouse embryos lacking the erythropoietin receptor. PNAS 93 9126-9131.

Kitamura T, Tange T, Terasawa T, Chiba S, Kuwaki T, Miyagawa K, Piao YF, Miyazono K, Urabe A \& Takaku F 1989 Establishment and characterization of a unique human cell line that proliferates dependently on GM-CSF, IL-3, or erythropoietin. Fournal of Cellular Physiology 140 323-334.

Lee SJ, Talamantes F, Wilder E, Linzer DIH \& Nathans D 1988 Trophoblastic giant cells of the mouse placenta as the site of proliferin synthesis. Endocrinology 122 1761-1768.

Lennon G, Auffray C, Polymeropoulos M \& Soares MB 1996 The IMAGE Consortium: an integrated molecular analysis of genomes and their expression. Genomics 33 151-152.

Letsky EA 1995 Erythropoiesis in pregnancy. Fournal of Perinatal Medicine 23 39-45.

Lin J \& Linzer DIH 1998 Regulation of erythropoiesis by mouse placental prolactin-like proteins. Program of the 80th
Annual Meeting of The Endocrine Society 1998, New Orleans, LA, USA (Abstract P3-463).

Lin J \& Linzer DI 1999 Induction of megakaryocyte differentiation by a novel pregnancy-specific hormone. Fournal of Biological Chemistry 274 21485-21489.

Lin CS, Lim SK, D’Agati V \& Costantini F 1996 Differential effects of an erythropoietin receptor gene disruption on primitive and definitive erythropoiesis. Genes and Development 10 154-164.

Lin J, Poole J \& Linzer DI $1997 a$ Three new members of the mouse prolactin/growth hormone family are homologous to proteins expressed in the rat. Endocrinology 138 5541-5549.

Lin J, Poole J \& Linzer DI $1997 b$ Two novel members of the prolactin/growth hormone family are expressed in the mouse placenta. Endocrinology 138 5535-5540.

Linzer DIH \& Fisher SJ 1999 The placenta and the prolactin family of hormones: regulation of the physiology of pregnancy. Molecular Endocrinology 13 837-840.

Liu X, Robinson GW, Gouilleux F, Groner B \& Hennighausen L 1995 Cloning and expression of Stat 5 and an additional homologue (Stat5b) involved in prolactin signal transduction in mouse mammary tissue. PNAS 92 8831-8835.

McGann JK, Silver L, Liesveld J \& Palis J 1997 Erythropoietin-receptor expression and function during the initiation of murine yolk sac erythropoiesis. Experimental Hematology 25 1149-1157.

Moritz KM, Lim GB \& Wintour EM 1997 Developmental regulation of erythropoietin and erythropoiesis. American Fournal of Physiology 273 R1829-R1844.

Müller H, Ishimura R, Orwig KE, Liu B \& Soares MJ $1998 a$ Homologues for prolactin-like proteins A and B are present in the mouse. Biology of Reproduction 58 45-51.

Müller H, Orwig KE \& Soares MJ $1998 b$ Identification of two new members of the mouse prolactin gene family. Biochimica et Biophysica Acta 1396 251-258.

Müller H, Dai G \& Soares MJ 1998c Placental lactogen-I (PL-I) target tissues identified with an alkaline phosphatasePL-I fusion protein. Fournal of Histochemistry and Cytochemistry 46 737-743.

Müller H, Liu B, Croy BA, Head JR, Hunt JS, Dai G \& Soares MJ 1999 Uterine natural killer cells are targets for a trophoblast cell-specific cytokine, prolactin-like protein-A. Endocrinology 140 2711-2720.

Onishi M, Nosaka T, Misawa K, Mui AL, Gorman D, McMahon M, Miyajima A \& Kitamura T 1998 Identification and characterization of a constitutively active STAT5 mutant that promotes cell proliferation. Molecular and Cellular Biology 18 3871-3879.

Orwig KE, Ishimura R, Müller H, Liu B \& Soares MJ 1997 Identification and characterization of a mouse homolog for decidual/trophoblast prolactin-related protein. Endocrinology 138 5511-5517.

Sawyer ST, Krantz SB \& Sawada K 1989 Receptors for erythropoietin in mouse and human erythroid cells and placenta. Blood 74 103-109.

Schneider H \& Malek A 1995 Lack of permeability of the human placenta for erythropoietin. Fournal of Perinatal Medicine 23 71-76.

Silver L \& Palis J 1997 Initiation of murine embryonic erythropoiesis: a spatial analysis. Blood 89 1154-1164.

Soares MJ, Dai G, Cohick CB, Müller H \& Orwig KE $1998 a$ The rodent placental prolactin family and pregnancy. In Endocrinology of Pregnancy, pp 145-176. Ed. FW Bazer. Totowa, NJ: Humana Press Inc.

Soares MJ, Müller H, Orwig KE, Peters TJ \& Dai G $1998 b$ The uteroplacental prolactin family and pregnancy. Biology of Reproduction 58 273-284. 
Socolovsky M, Fallon AE \& Lodish HF 1998 The prolactin receptor rescues EpoR - / - erythroid progenitors and replaces EpoR in a synergistic interaction with c-kit. Blood 92 1491-1496.

Socolovsky M, Fallon AE, Wang S, Brugnara C \& Lodish HF 1999 Fetal anemia and apoptosis of red cell progenitors in Stat $5 \mathrm{a}-/ 5 \mathrm{~b}-$ mice: a direct role for Stat5 in Bcl-X(L) induction. Cell 98 181-191.

Tanaka T, Shiu RP, Gout PW, Beer CT, Noble RL \& Friesen HG 1980 A new sensitive and specific bioassay for lactogenic hormones: measurement of prolactin and growth hormone in human serum. Fournal of Clinical Endocrinology and Metabolism 51 1058-1063.

Teglund S, McKay C, Schuetz E, Van Deursen JM, Stravopodis D, Wang D, Brown M, Bodner S, Grosveld G \& Ihle JN 1998 Stat5a and Stat5b proteins have essential and nonessential, or redundant, roles in cytokine responses. Cell 93 841-850.

Tilbrook PA, Bittorf T, Callus BA, Busfield SJ, Ingley E \& Klinken SP 1996 Regulation of the erythropoietin receptor and involvement of JAK2 in differentiation of J2E erythroid cells. Cell Growth and Differentiation 7 511-520.

Wu H, Liu X, Jaenisch R \& Lodish HF 1995 Generation of committed erythroid BFU-E and CFU-E progenitors does not require erythropoietin or the erythropoietin receptor. Cell 83 59-67.

Ymer S, Tucker WQ, Sanderson CJ, Hapel AJ, Campbell HD \& Young IG 1985 Constitutive synthesis of interleukin-3 by leukaemia cell line WEHI-3B is due to retroviral insertion near the gene. Nature 317 255-258.

REVISED MANUSCRIPT RECEIVED 8 June 2000 